\title{
Adenoid squamous cell carcinoma of right gingivobuccal sulcus - A rare case report
}

\author{
Pankaj Pande', Prakash Murigeppa Patil', Mihir J. Bhalodia', Jyotirling Savle ${ }^{1}$, Himanshu Mulay ${ }^{1}$ \\ ${ }^{1}$ Department of Pathology, BLDE University, Shri B M Patil Medical College, Hospital and Research Center, Bijapur District, \\ Karnataka State, India
}

\section{A B S T R A C T}

Oral cancer is the sixth most common malignancy in the world and third most common in southeast Asia. When it does occur, it is most commonly seen on the tongue or lip. Cancers of the gingivobuccal sulcus are uncommon and reported infrequently. Here we report a case of 35 years female diagnosed with adenoid squamous cell carcinoma of right gingivobuccal sulcus. Most of these cancers are locally advanced stage due to delay in presentation and ignorance of population.

\section{Access this article online}

Website:

http://nepjol.info/index.php/AJMS

DOI: 10.3126/ajms.v6i3.10793

Key words: Oral cancer, Gingivobuccal sulcus, Adenoid squamous cell carcinoma

\section{INTRODUCTION}

Oral cancer is the sixth most common malignancy in the world and third most common in southeast Asia. ${ }^{1}$ The prevalence varies with ethnicity, geographic distribution, and socio-economic differences. The disproportionately higher prevalence of head and neck neoplasm in India may be due to the use of tobacco in various forms. ${ }^{1,2}$ The incidence is two to three times more frequent in men than women owing to increased tobacco abuse. ${ }^{2}$ Gingivobuccal sulcus, hard palate and maxilla are uncommon and diagnosed at an advanced stage due to delay in presentation. ${ }^{1}$ These cancers are metastasized rapidly to submandibular and deep cervical lymph nodes and also responsible for death in many cases. In this article we report a rare case of adenoid squamous cell carcinoma of right gingivobuccal sulcus.

\section{CASE REPORT}

A 35 years female presented with ulcerative growth on right gingivobuccal sulcus, infiltrating up to mandible, measuring $2 \times 2 \mathrm{~cm}$ since 1 year. There was history of chewing gutkha 15 to 20 packets per day since 10 years, ulcer which is slow growing with intermittent bleeding. Ulcerated lesion with hard, raised edges invading the underlying tissue

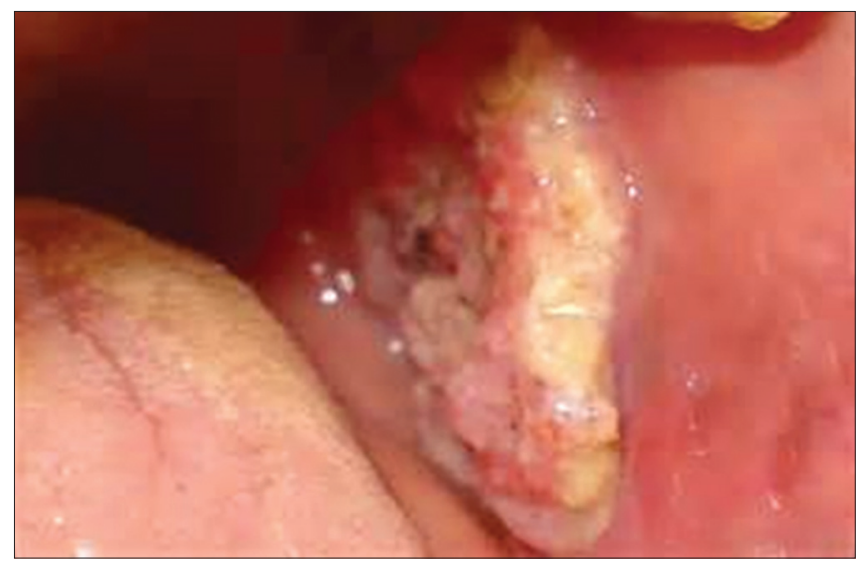

Figure 1: On Examination photograph showing Ulcerated lesion with hard, raised edges

(Figure 1) Laboratory studies revealed a haemoglobin of $9.5 \mathrm{gm} / \mathrm{dl}$ and white blood cell count of 15,000 cells $/ \mathrm{mm}^{3}$. Inflammatory markers were within the normal limits, ESR was $18, \mathrm{C}$-reactive protein was negative. A lytic lesion of the right mandibular alveolus was noted on periapical radiographs. Excision of the mass done and specimen send for histopathology. (Figure 2).

\section{Histopathology}

Histopathology shows loss of intercellular adhesion and many degenerating acantholytic cells seen, tumor tissue 


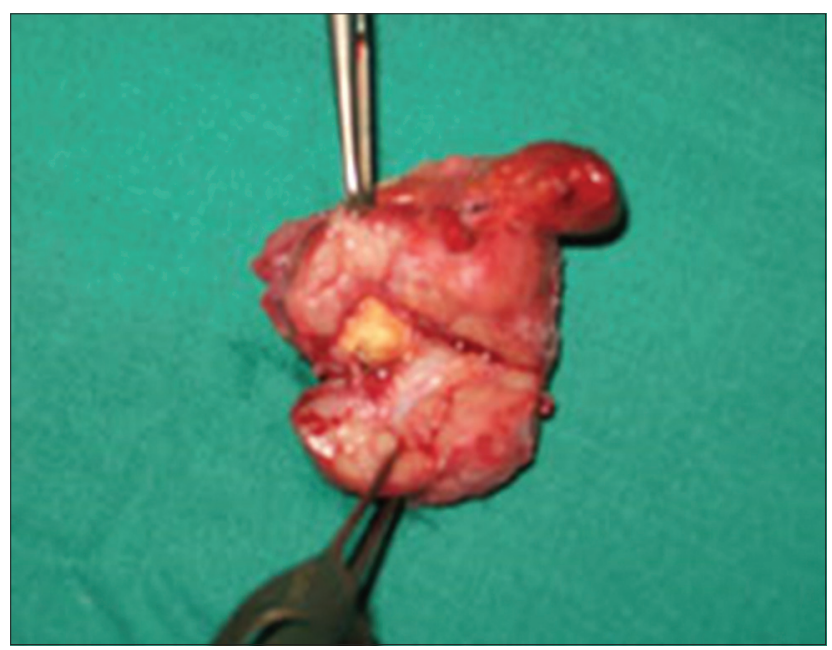

Figure 2: Gross photograph of mass

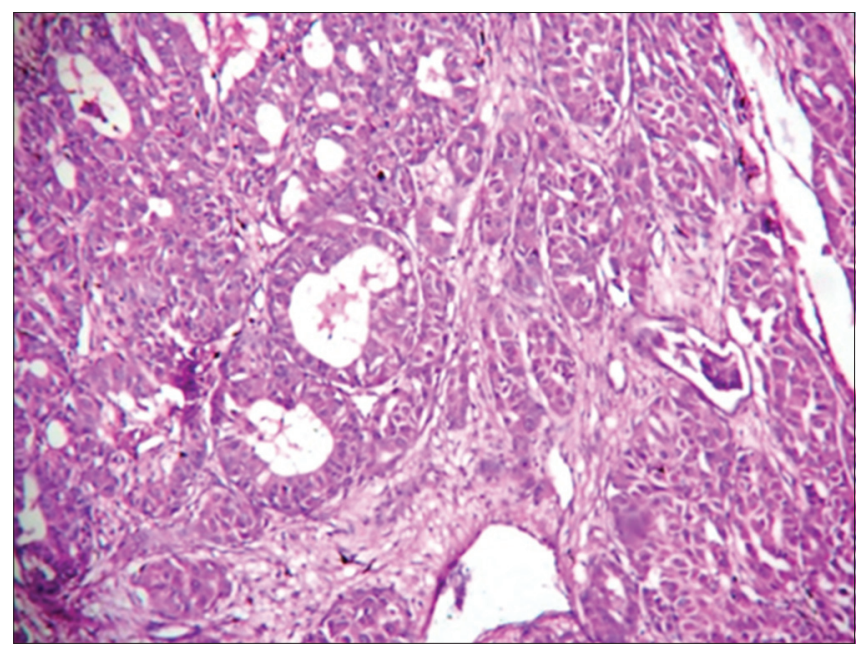

Figure 3: H\&E stain shows glandular and nest pattern of tumor tissue.(10x)

arranged in glandular and nests pattern. (Figures 3 and 4). The individual cells are polygonal with round to oval hyperchromatic nuclei and prominent nucleoli with abundant eosinophilic cytoplasm. At foci squamous differentiation is seen (Figure 5).

\section{DISCUSSION}

Worldwide, cancer of the head and neck is relatively uncommon compared with other tumor locations and two-thirds of the deaths occur in men. ${ }^{1}$ Tumor of upper alveolar ridge and hard palate is not very common with upper gingival cancers constituting nearly $3.5 \%$ of all oral malignancies, age of presentation mainly in $4^{\text {th }}-5^{\text {th }}$ decade. ${ }^{1,2}$ The risk factors are alcohol and tobacco both of which act as local irritants to the mucosa. ${ }^{3}$ In India these are among the top five cancers and highest among woman because of habitual betel nut chewing. The dominant side of these tumors is the left side. ${ }^{4}$ The cause is unknown but may be

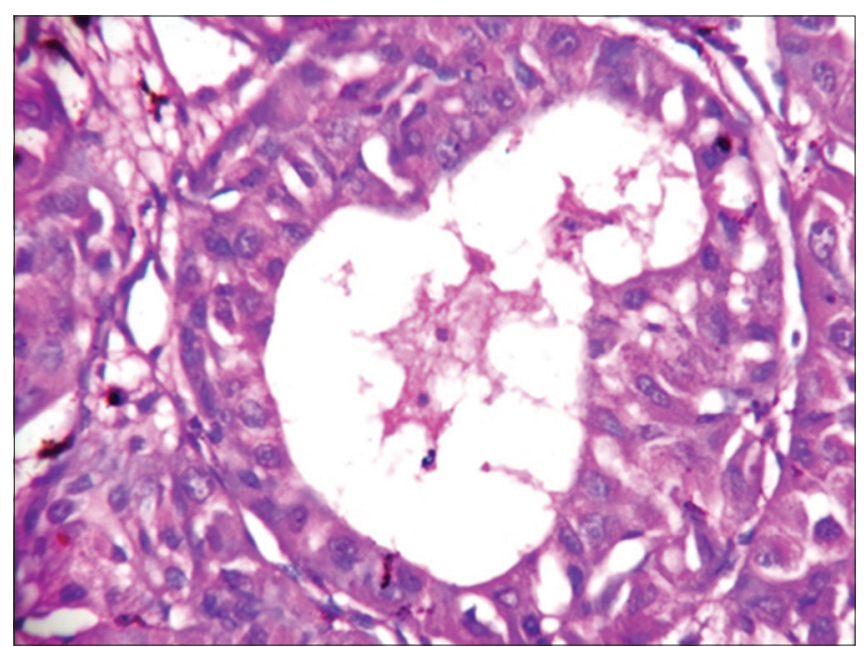

Figure 4: H\&E stain shows acantholytic cells (40x)

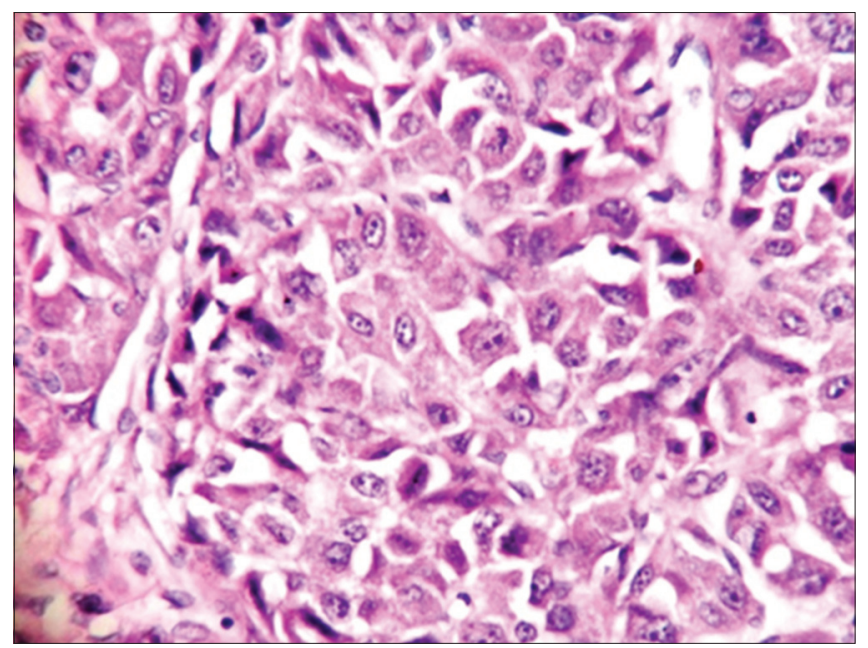

Figure 5: H\&E Stain shows foci of squamous differentiation (40x)

from the betel nut chewing pattern as most of the people were right side chewers. ${ }^{4}$

Most common presenting symptom in our case was nonhealing oral ulcer. This was in contrast to a similar article from the west where most of the patients presented with pain. This may reflect the ignorance to health related issues in our population. This finding is similar to other studies which stressed on the fact that patients with oral cancer have delayed presentation which makes the treatment difficult and sometimes unsuccessful. ${ }^{3,4}$

After the surgical excision tissue mass send for histopathology and Adenoid squamous cell carcinoma diagnosis made on histopathology. Adenosquamous carcinoma which was the close differential diagnosis of adenoid squamous cell carcinoma. Although both are locally aggressive tumors and mainly metastasized rapidly to submandibular and deep cervical lymph nodes, and death can occurs in spite of surgery and radiotherapy., 


\section{CONCLUSION}

Gingivobuccal sulcus, hard palate and maxilla cancers are uncommon and diagnosed at an advanced stage due to delay in presentation and ignorance of population. Most cancers are locally advanced and death can occurs in spite of surgery and radiotherapy.

\section{REFERENCES}

1. Kumar V, Sindhu VA, Rathanaswamy S, Jain J, Akhtar N,
Gupta S, et al. Cancers of upper gingivobuccal sulcus, hard palate and maxilla: A tertiary care centre study in North India. Nat J Maxillofac Surg 2013; 4: 202-205.

2. Cabral LA, Carvalho LF, Salgado JP and Brandao AH. Gingival Squamous Cell Carcinoma: a Case Report. J Oral Maxillofac Res 2010; 1:6-10.

3. Binahmed A, Charles M, Campisi P, Carmichael RP and Sandor GK. Primary Squamous Cell Carcinoma of the Maxillary Alveolus in a 10-year-old Girl JCDA, 2007; 73: 715718.

4. Andrea $C$, Alessandro $G$ and Mara R. Ulcerated pedunculated mass of the maxillary gingival. Oral Surg Oral Med Oral Pathol Oral Radiol Endod 2009; 107(3):313-317.

\footnotetext{
Authors Contribution:

PP - Concept, definition of intellectual content; PMP - Definition of intellectual content, literature search, manuscript revision; MJB - Literature search, clinical data \& photograph collection, manuscript preparation; JS - Photograph collection, manuscript preparation. HM - Photograph collection, manuscript preparation.

Source of Support: Nil, Conflict of Interest: None declared.
} 